\title{
Esthetic Rehabilitation in Early Childhood Caries: A Case Report
}

\author{
Gabriela M Goldenfum ${ }^{1}$, Jonas de Almeida Rodrigues ${ }^{2}$
}

\begin{abstract}
Premature loss or severely destruction of upper primary anterior teeth by early childhood caries (ECC) is a challenge for the pediatric dentist. In the anterior region, esthetics is an important concern along with function and space management. Tooth rehabilitation in this region becomes fundamental. The purpose of this report was to present a case of a 4-year-old child with the early loss of both central upper incisors and caries lesions on both upper lateral incisors. Both 51 and 61 were extracted due to ECC. The patient was rehabilitated with a fixed esthetic space maintainer and the vital lateral upper incisors, destroyed by ECC, restored with direct composite resin veneers. The final result reestablished local, systemic, psychological, aesthetic, and social problems of the child.
\end{abstract}

Keywords: Early childhood caries, Esthetic, Space maintainer.

International Journal of Clinical Pediatric Dentistry (2019): 10.5005/jp-journals-10005-1611

\section{INTRODUCTION}

Premature loss and severe destruction of primary teeth due to caries is a common occurrence in children under 6-years-old, known as early childhood caries (ECC). This is, by nature, rampant, acute, and progressive. If the progression of the caries condition is not interrupted, serious local, systemic, psychological, aesthetic, and social problems could be resulted. ${ }^{1}$

The restoration of primary maxillary incisors severely destroyed by ECC is a challenge for pediatric dentists, due to child behavior and age. Various esthetic options are available for restoring or replacing it and it depends on the clinician to make the best decision for each individual situation. Adhesive restorations, such as direct composite resin veneer, allow clinicians to restore and to create minimally invasive preparations, thereby preserving the tooth structure. ${ }^{2}$ In more severe cases, when extractions are needed, the space should be maintained functionally as well as aesthetically by a suitable space maintainer. This rehabilitation should provide good longevity, without interfering with the normal eruption process. ${ }^{3}$

This article reports a case of an esthetic rehabilitation of maxillary primary anterior teeth of a 4-year-old patient with ECC treated at the Pediatric Dentistry Clinic of the School of Dentistry of the Federal University of Rio Grande do Sul (UFRGS), Brazil.

\section{Case Description}

A 4-year-old female child was brought to the Pediatric Dentistry Clinic of the School of Dentistry of the Federal University of Rio Grande do Sul (UFRGS), Brazil, for esthetic rehabilitation of anterior teeth. The patient's general health status and past medical history were satisfactory. The mother reported that the primary incisors were darkened and nonuniform, and that the girl would start in the school next year and this clinic situation could disturb her.

All posterior teeth had active cavitated carious lesions and/or extensive restorations showing a past history of ECC. In the anterior region, teeth $52,51,61$, and 62 had extensive restorations associated with carious lesions. All canines have active not cavitated carious lesions and the lower incisors $(72,71,81$, and 82) were healthy (Fig. 1). In the radiographic examination, none of the posterior
${ }^{1,2}$ Department of Pediatric Dentistry, Federal University of Rio Grande do Sul, Porto Alegre, Rio Grande do Sul, Brazil

Corresponding Author: Gabriela M Goldenfum, Department of Pediatric Dentistry, Federal University of Rio Grande do Sul, Porto Alegre, Rio Grande do Sul, Brazil, Phone: +55 51 33085027, e-mail: gabigolden@hotmail.com How to cite this article: Goldenfum GM, de Almeida Rodrigues J, et al. Esthetic Rehabilitation in Early Childhood Caries: A Case Report. Int J Clin Pediatr Dent 2019;12(2):157-159.

Source of support: Nil

Conflict of interest: None

teeth presented pulpal involvement. Teeth 51 and 61 presented irreversible pulpal involvement with an extensive root resorption and considerable bone loss around them, associated with draining sinus, and tooth extraction was indicated.

The treatment plan was settled and explained to the mother, who signed an approved informed consent form authorizing the treatment as well as disclosure and publishing of this case report. Initial dental care consisted of removal of hopeless teeth (51 and 61 ) and intervention in etiologic factors of caries disease as plaque control, diet, and rational use of fluoride.

All posterior restorative treatments were conducted undergoing the selective caries removal technique ${ }^{4}$ and a composite resin was used for the restoration. In the anterior region, teeth 52 and 62 had unsatisfactory restorations and 52 have a dentin lesion in the palatal surface, presenting them dark and not aesthetic. A fixed functional space maintainer replacing both teeth 51 and 61 was planed, and direct composite resin veneers in 52 and 62 were placed.

Teeth 52 and 62 were worn on the vestibular surface to remove old restorations and to have space to restore using direct composite resin veneers. The color was selected ( $\mathrm{A} 1$ color-Vitta scale) and $37 \%$ phosphoric acid, AdperSingle Bond 2 (3M Espe ${ }^{\circledast}$, Brazil), and resin Z350 XT (3M Espe ${ }^{\oplus}$, Brazil) were used. Finishing and polishing were performed using aluminum-oxide discs (Sof-Lex, 3M Espe ${ }^{\circledR}$, Brazil), enhance burs (Dentsply ${ }^{\circledR}$, Brazil), and finishing pastes with felt discs (TDV ${ }^{\circledR}$, Brazil). The procedures were performed in relative isolation using cotton rolls without the need for anesthesia (Fig. 2).

(c) The Author(s). 2019 Open Access This article is distributed under the terms of the Creative Commons Attribution 4.0 International License (https://creativecommons. org/licenses/by-nc/4.0/), which permits unrestricted use, distribution, and non-commercial reproduction in any medium, provided you give appropriate credit to the original author(s) and the source, provide a link to the Creative Commons license, and indicate if changes were made. The Creative Commons Public Domain Dedication waiver (http://creativecommons.org/publicdomain/zero/1.0/) applies to the data made available in this article, unless otherwise stated. 


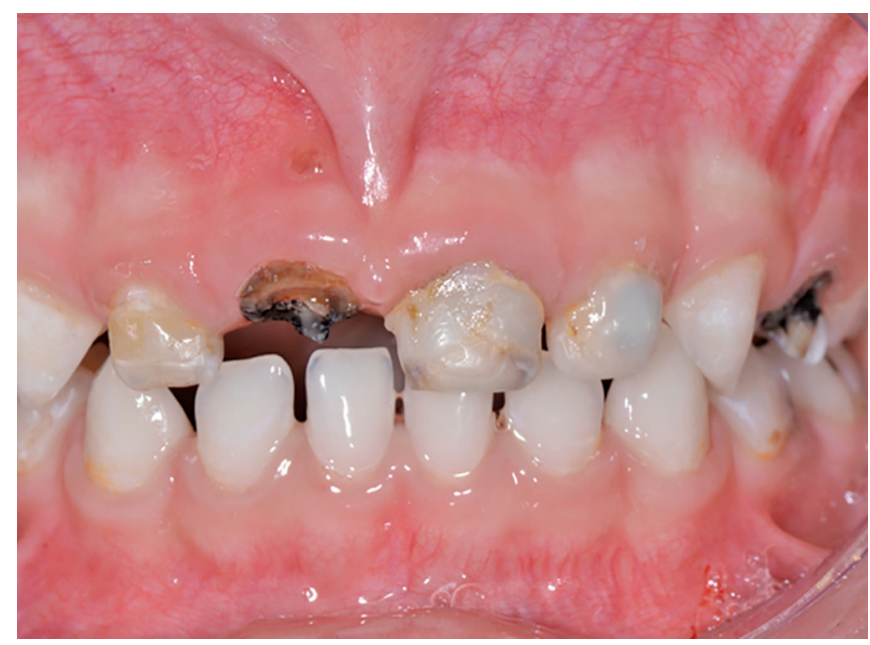

Fig. 1: Initial examination—anterior region—frontal view

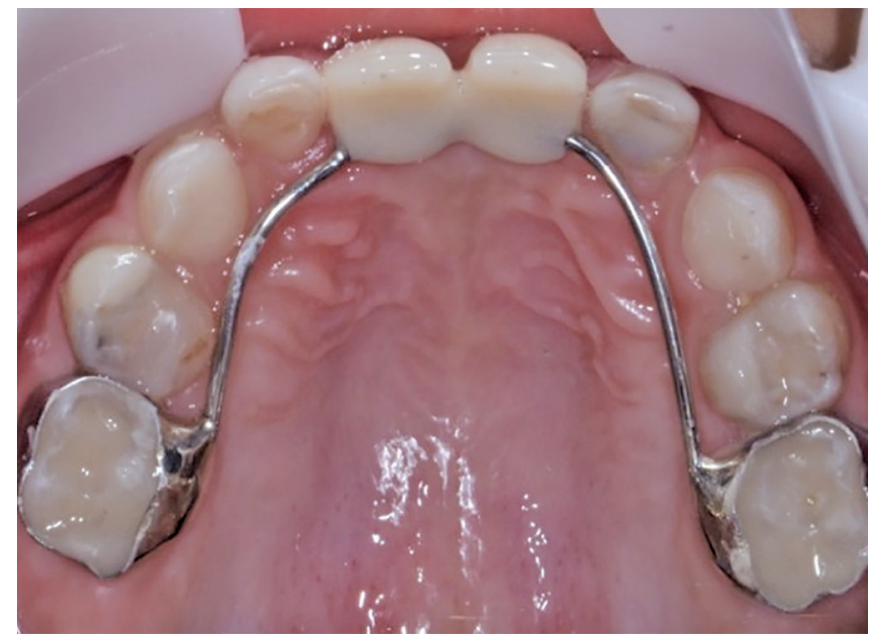

Fig. 3: Fixed esthetic space maintainer replacing 51 and 61 after being cemented-occlusal view

For the fixed esthetic space maintainer, the preoperative occlusal evaluation was performed. Appropriated preformed orthodontic bands were adapted on teeth 55 and 65 followed by alginate impression to make the working cast. A space maintainer was confectioned using acrylic stock teeth compatible with primary teeth (51 and 61-A1 color-Vitta scale) fixed in an orthodontic wire adapted on the palatal arch in the $U$ form and soldered to the bands. The space maintainer was cemented on 55 and 65 with the glass ionomer cement (Vitremer, $3 \mathrm{M}$ Espe ${ }^{\oplus}$, Brazil) and occlusion was checked for any premature contact (Fig. 3). The patient was advised to avoid chewing of hard food and to maintain proper oral hygiene. The mother was informed that the appliance would be removed when the permanent maxillary central incisors started erupting, to prevent interference. The patient was recalled after 1 week to check the integrity of the space maintainer and its adaptation (Fig. 4). The check-up will be conducted every 3 months.

\section{Discussion}

When an anterior primary tooth is lost earlier than expected, the permanent successor's development and eruption may be altered and, thus, the arch length discrepancy is increased, raising the

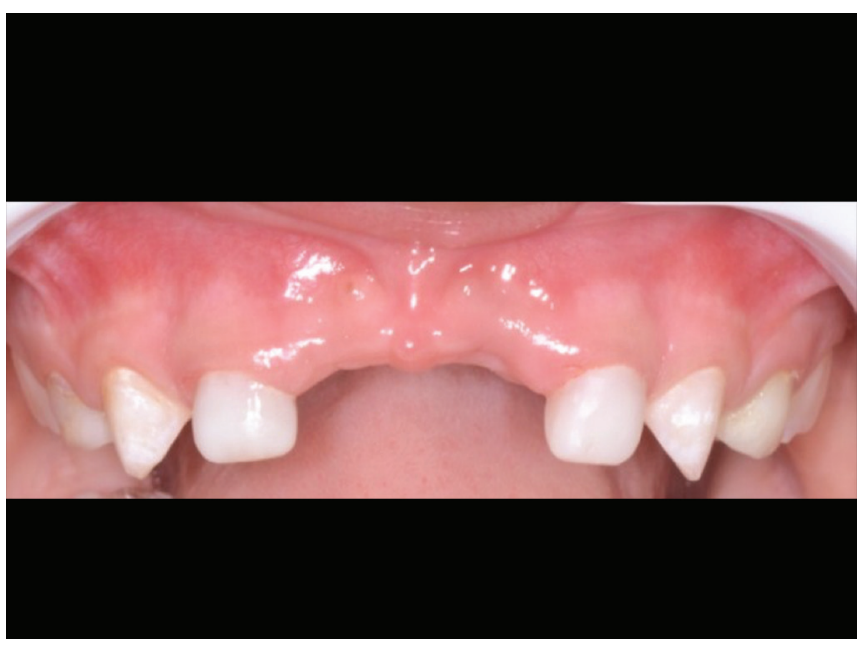

Fig. 2: Direct composite resin veneer teeth 52 and 62-frontal view

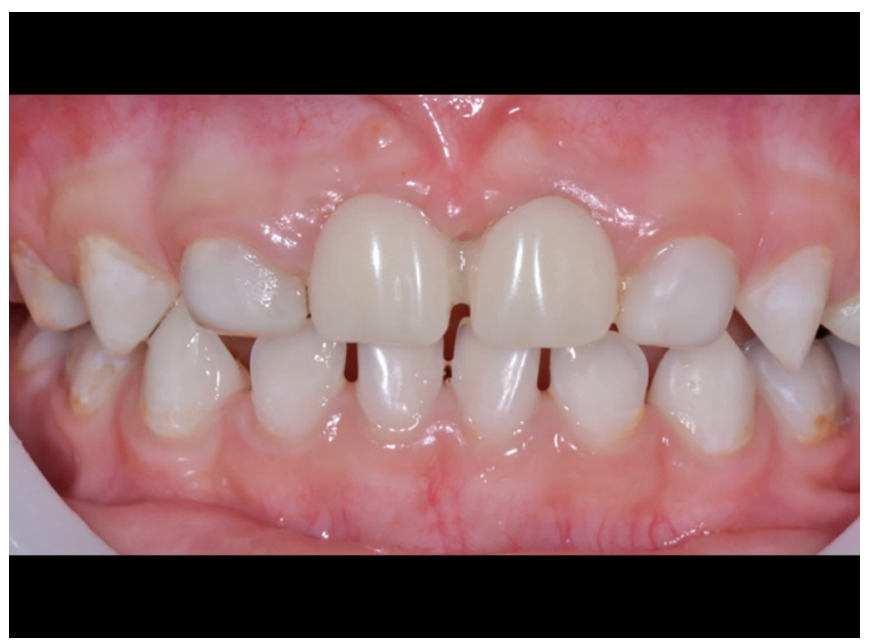

Fig. 4: Final result-frontal view

potential for developing malocclusion at a later stage. The space should be maintained as soon as possible. ${ }^{3,5,6}$

The primary incisors are lost most commonly at the age of 2 to 4 years, because of ECC and/or trauma. ${ }^{6}$ The lost at this phase may result in psychological disturbances and affect the child self-esteem and socialization during an important phase of development, especially if these defects are visible during speech and laughter. ${ }^{5,6}$

Careful consideration should be taken for placement of any space maintainer in incisor segment. Depends on the child's stage of dental development, dental arch involved, primary teeth missing, and which teeth they are. ${ }^{3}$ The space maintainer prevents overeruption of antagonist, restores physiological mastication, allows for physiological maxillary growth, should be hygienic, have a good durability, and have a low cost. ${ }^{7}$

The removable space maintainer is the most commonly employed when an anterior tooth is prematurely lost. Unfortunately, there are a number of drawbacks associated with this use, like dependency on the patient for the success, child may not wear it, accidental ingestion or aspiration, breakage, and loss. Besides, a removable appliance may have a deleterious effect on the involved 
soft tissue and periodontal. So, the efficiency and effectiveness of the space maintenance could be compromised. ${ }^{6}$

The use of fixed prostheses in children could be limited by the arch modifications that result from the development of primary and mixed dentition occlusions. However, a period of stability exists in which a fixed appliance may be used. This period, when children are between the ages of 3 and 5.5 years, is the time in which the primary arch is completed and the sagittal and transverse dimensions are unaltered. ${ }^{5}$ In the present case, the patient was 4 years, an indicated and stable period to do it.

Patil $^{8}$ affirmed that the fixed space maintainer used to replace deciduous central incisor reveals a good success with the improvement of aesthetic and function with fewer requirements of patient cooperation and less irritation to the oral tissue. Khare affirmed that an aesthetic space maintainer has been found to have a much wider acceptability and compliance of wearing the appliance by the pediatric dental patients.

In the present case, a minimum amount of palatal coverage was done, causing no or less irritation to the soft tissues. Banding of molars was done to improve the strength instead of bonding. The total time for confection and installation of the space maintainer was two visits and was an easy and rapid technique. The space maintainer did not appear to be flexible and the acrylic teeth were well supported by the gingiva. Apart from that, teeth 55 and 65 were healthy and away from the exfoliation period. The limitations like improper oral hygiene and breakage could be overruled by proper education and motivation of the patient and the parents. The success of the treatment depends on the long-term follow-up due to eruption of the permanent teeth and the growth and development of the maxilla.

The patient and the parents were very satisfied with the final results. In the first revision visit, the facial expression of the patient was remarkable, the change in the self-esteem, it was evident. The parents related no difficult with the fixed space maintainer, both for speaking and for eating, and the child has adapted very well.

Regarding the direct composite veneer done in the upper lateral incisors (52 and 62), Araújo ${ }^{9}$ affirmed that in the deciduous dentition is indicated in cases of almost total recovery of dental structure caused by caries or trauma. Correa ${ }^{10}$ described as a relatively simple technique, with low cost, little mutilating, it needs reduced clinical chair time, and does not cause a relapse.
Resin-based composites demonstrate the best strength, wear resistance, esthetics, and color-matching capabilities and are often the first choice of many clinicians for restoring anterior teeth. However, these materials are the most technique sensitive, require the use of acid etching and bonding agents, and are intolerant to moisture and/or hemorrhage. ${ }^{2}$

In the present case, the direct composite resin veneer appeared to be a good solution for the esthetic. The patient was already caries controlled and had good hygiene habits, being well adhered to the treatment proposed.

\section{References}

1. American Academy of Pediatric Dentistry. Policy on Early Childhood Caries (ECC): Classifications, Consequences, and Preventive Strategies. Oral Health Policies. Reference Manual. 2014/2015; 36(6).

2. Liporoni $P$, Pimenta $A$, et al. Direct composite resin veneer. Rev. $A B O$ Nac 1998 Out-Nov;6(5):319-322.

3. Kwan SYL, Petersen PE, et al. Health-promoting schools: An opportunity for oral health promotion. Bull world Health Organ 2005;83(9):677-685. DOI: /S0042-96862005000900013. .

4. Casagrande L, Dalpian DM, et al. Randomized clinical trial of adhesive restorations in primary molars. 18-month results. Am J Dent 2013 Dec;26(6):351-355.

5. de Sant'Anna GR, Guaré Rde O, et al. Primary anterior tooth replacement with a fixed prosthesis using a precision connection system: a case report. Quintessence Int 2002 Apr;33(4):303-308.

6. Goenka P, Sarawgi A, et al. Simple Fixed Functional Space Maintainer. Int J Clin Pediatr Dent 2014 Sep-Dec;7(3):225-228. DOI: 10.5005/ jp-journals-10005-1272.

7. Marwaha $M$, Bhat $M$, et al. Building-up a Smile in a 5 -Year-Old Child: A Case Report. Int J Clin Pediatr Dent 2012 May;5(2):151-154. DOI: 10.5005/jp-journals-10005-1156.

8. Patil RB, Rachappa MM. A simple modification of fixed space maintainers for replacement of an avulsed maxillary primary central incisor. Int J Dental Clin 2011;3:117.

9. Araújo FB, et al. Tratamento restaurador das lesões de cárie. Toledo OA. Odontopediatria - Fundamentos para a prática clínica, 3rd ed. São Paulo: Premier, 2005; pp. 163-214.

10. Correa MS, Ciamponi AL, et al. Esthetical solutions for chromatical alterations in anterior deciduous teeth. Rev Assoc Paul Cir Dent 1990 Jul-Aug;44(4):201-203. 